gall stones the fence might have been more than half built by now.

The problem is that we surgeons enjoy rescuing people who fall over cliffs and are fairly well paid for it. When the fence is built and gall stones prevented, as they will be in the not too distant future, surgeons' attention will have to be diverted to other patients with other conditions. This is nothing new in the history of surgery-why else are many cardiac units situated in old tuberculosis hospitals? Thoracic surgeons adapted very quickly when thoracoplasties and phrenic crushes were no longer needed and took up cardiac surgery instead.

\section{Who should have their gall bladders removed?}

The important every day question for all clinicians is: Who needs treatment for gall stones? The question has become particularly acute over the past few years since ultrasonography can detect stones so easily. When asked to scan the pelvis ultrasonographers have the annoying habit of waving their ultrasound wands over the right hypochondrium. Many patients come to a clinic with a cheerful smile on their faces saying, "At last they have found the cause of the pain that I have been telling my general practitioner about for years. It is all due to my gall stones." When asked where the pain is they point to the suprapubic region or to the left iliac fossa and the smile fades when they are told that it probably has nothing to do with their gall stones. Removing the gall bladder, even through the smallest incision, can provide no guarantee that these symptoms will be cured.

Jorgensen's prevalence study in Denmark on an unselected population found that there was no significant difference in pain characteristics and pain location between those with a normal gall bladder and those with gall stones (so long as the patients with gall stones were not aware they had them).' ${ }^{1}$ The prevalence of pain in patients who had undergone cholecystectomy was in fact significantly higher than in those who had not. But surely in practice we are all agreed about who should have their gall bladders removed.

Unfortunately, a recent study explodes this myth. Scott and Black showed the case histories of 252 patients who had undergone cholecystectomy to a panel of doctors of varying specialties and to a panel of surgeons. ${ }^{2}$ The mixed panel agreed that the operations were appropriate in $41 \%$ of cases and inappropriate in $30 \%$, whereas the surgeons agreed that $52 \%$ were appropriate and $2 \%$ inappropriate but could not agree on the remaining $46 \%$.

If half the operations should not be done at all, whether by open or laparoscopic techniques, the discussions about one less day in hospital or half an hour longer in the operating theatre pale into insignificance.

1 Jorgensen $T$. Abdominal symptoms and gallstone disease: an epidemiological investigation. Hepatology 1989;9:856-60.

2 Scott EA, Black N. Appropriateness of cholecystectomy. Ann Roy Coll Surg Eng 1992;74 (suppl):97-101.

\title{
Helping people with dementia feel at home
}

\section{Stuart Handysides}

In December 1992 an NHS unit designed specifically for elderly people with dementia opened at 210 Knight's Hill in south London. It provides residential and day hospital care for elderly people with dementia, many of whom would previously have occupied a ward at Cane Hill Hospital, a Victorian asylum. The need for such a service is increasing for two reasons. The number of elderly people is rising: in 1974 people over 75 made up $5 \%$ of the population ${ }^{1}$ but in 1989 they made up $7 \% .^{2}$ Closure of mental hospitals began in the 1950 s, but as psychiatric patients were discharged into

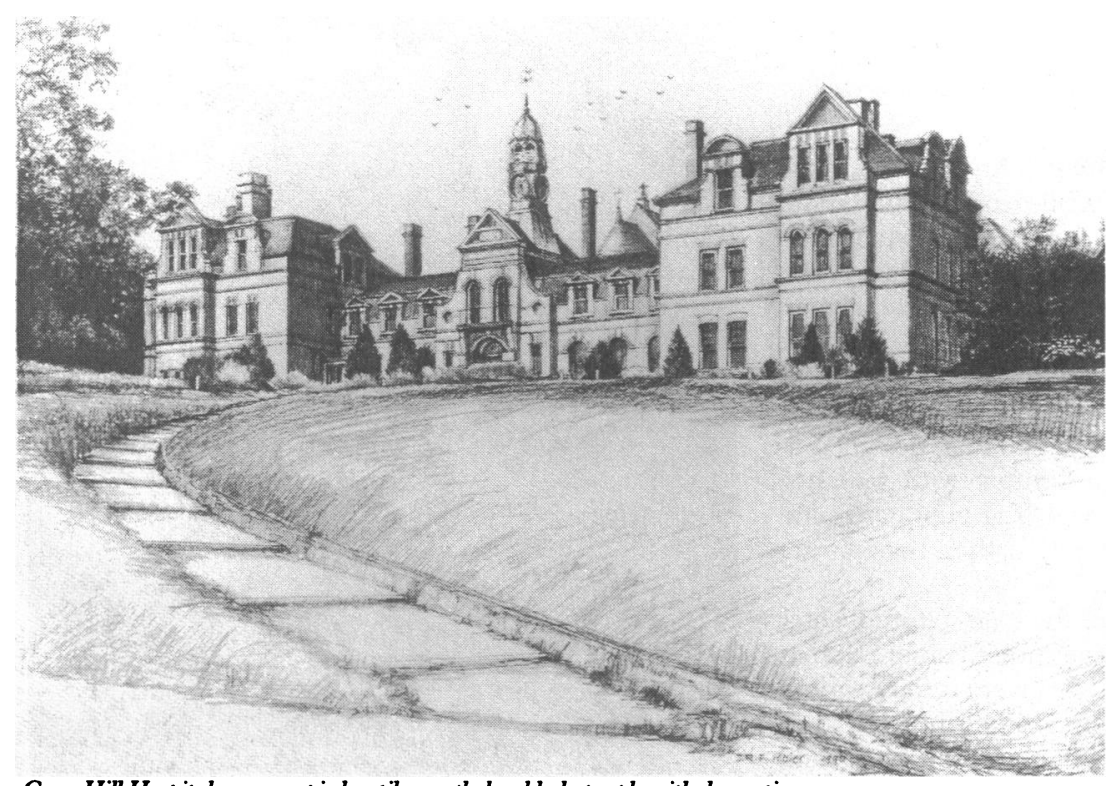

Cane Hill Hospital was occupied until recently by elderly people with dementia the community their places were taken by elderly people with dementia. This has delayed the closure of some hospitals; for those that are left, though, it is now imminent. Knight's Hill incorporates features and a philosophy that may become a benchmark for future homes.

\section{The Knight's Hill project}

Ten years ago in Camberwell, after assessment at the Maudsley or Dulwich Hospitals, demented patients who could not be looked after at home usually went to Cane Hill Hospital (fig), an old asylum several miles out of London with "loony bin" connotations for patients and their relatives. In preparation for Cane Hill's closure, Age Concern Southwark opened a nursing home for 30 people in association with the Maudsley Hospital. At the same time, the Knight's Hill project began.

Camberwell Health Authority had a former tuberculosis hostel in the Maudsley catchment area. On this site, with the prospect of monies arising from the sale of Cane Hill, they commissioned a building for the care of demented patients. Unlike the long wards of Cane Hill, it would provide residents with their own rooms. It would also offer respite care and day hospital care for people with dementia living in the community.

The project members met over two years, and Knight's Hill opened in December 1992. Michael Manser, the architect, designed the unit on a cruciform plan, with an enclosed courtyard in the centre which leads out to four houses. Twelve people live in each of three of the houses, and the fourth provides space for day care, administration, the kitchen, and laundry. This kind of design is known as a group home and 


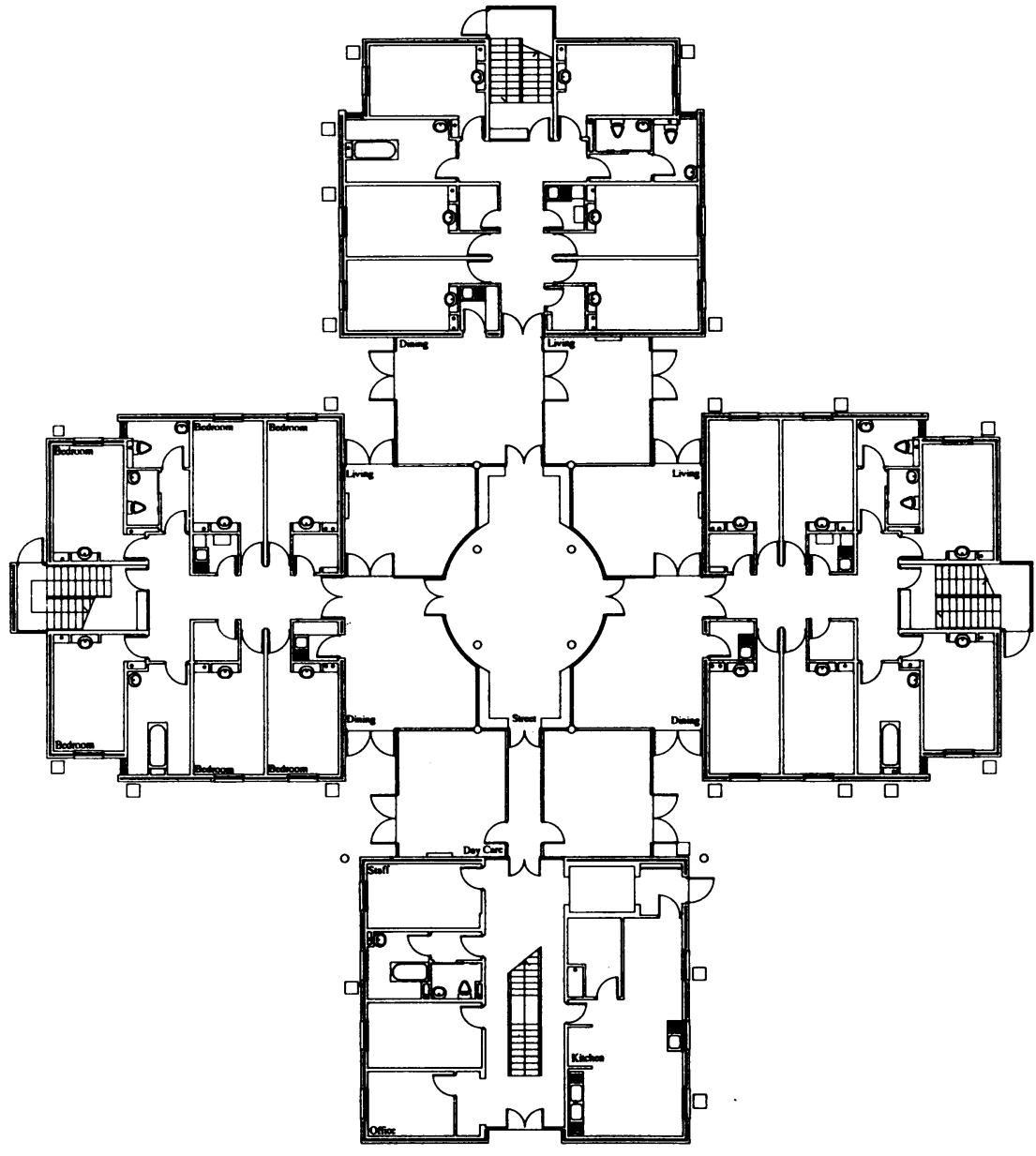

Ground floor plan of 210 Knight's Hill. (Courtesy of Michael Manser Associates Ltd)

provides all the activities of living, sleeping, and eating in a definable area for a particular group of residents. People find their way around a group home better than a communal home, where all the residents share a dining area and bedrooms line long corridors. ${ }^{3}$

The houses are colour coded to help residents remember where they are. The floors in different parts of the building feel and sound different, giving further clues. A green slate path leads from the road, through the front door and administrative house, into the communal courtyard: the idea is to create an indoor street, safe, warm, but separate from the houses that open on to it. Halls in the houses have wooden floors, with vinyl in bedrooms and dining rooms, and the sitting rooms are carpeted.

\section{Dignity as well as design}

The manager of Knight's Hill is John Stanbury, who joined the project last May. While enthusiastic about the building, he emphasises that good care depends on staff behaviour and attitudes. Although Knight's Hill is a hospital unit, it does not feel like a ward. Total staff outnumber patients by two to one, and they seem to be in constant contact with patients. Patients and staff share facilities and eat together. The nursing stations are scarcely more than walk in cupboards, designed to prevent nurses from avoiding contact with patients. Each patient has his or her own drug cupboard, and medicines are issued individually rather than at set times.

When choosing the furniture the team poured water over it and jumped on it to make sure it would last. $\mathbf{M r}$ Stanbury talked about the care that went into selection: "We initially wanted to have household divan beds in the bedrooms, but staff worried about their backs and EC regulations led to a compromise: hospital beds, but with polished head and footboards specially made. We offered a choice of five curtain and bedspread designs, and eight colours of lampshades. The patients are not always able to state their choice, but their relations appreciate it." The easy chairs look like tweed, but close inspection reveals non-slip, non-reflective vinyl. They give good lumbar support and have enclosed arms to prevent draughts. Tables have a contrasting border, more easily seen, and no sharp edges. Dining chairs are heavily built with arms, so a patient who drops off does not fall off.

There are two toilets for six bedrooms, and patients are encouraged to use them. Toilet doors are a different colour from other doors, a subtle hint: a person who cannot find the toilet may be incontinent, having forgotten what he or she was looking for. ${ }^{4}$ The management committee has to be convinced before the otherwise innocent comfy chair supplied to each bedroom is converted into a commode.

The building was designed to use natural light as much as possible. Bedroom windows have low sills so that residents can see the garden and surrounding houses while sitting. From the north house a panorama of London opens up, from Canary Wharf to the Houses of Parliament. The windows designed for the communal crossing area were larger than those than it now has. The planning department insisted that the building was squeezed to increase its distance from the north boundary. To avoid the delay of an appeal, changes were made which reduced the view and natural light for two of the houses.

\section{Highly dependent patients}

Dr Marisa Silverman, one of two consultant psychiatrists in charge of the unit, told me about the patients they were looking after. Many wander and can get lost, but the unit is designed to lead them back to where they started. The boundaries are secure, so they cannot reach the street. "One man," she said, "had previously set fire to curtains in a nursing home, and needs careful observation. Another woman is very distressed, unable

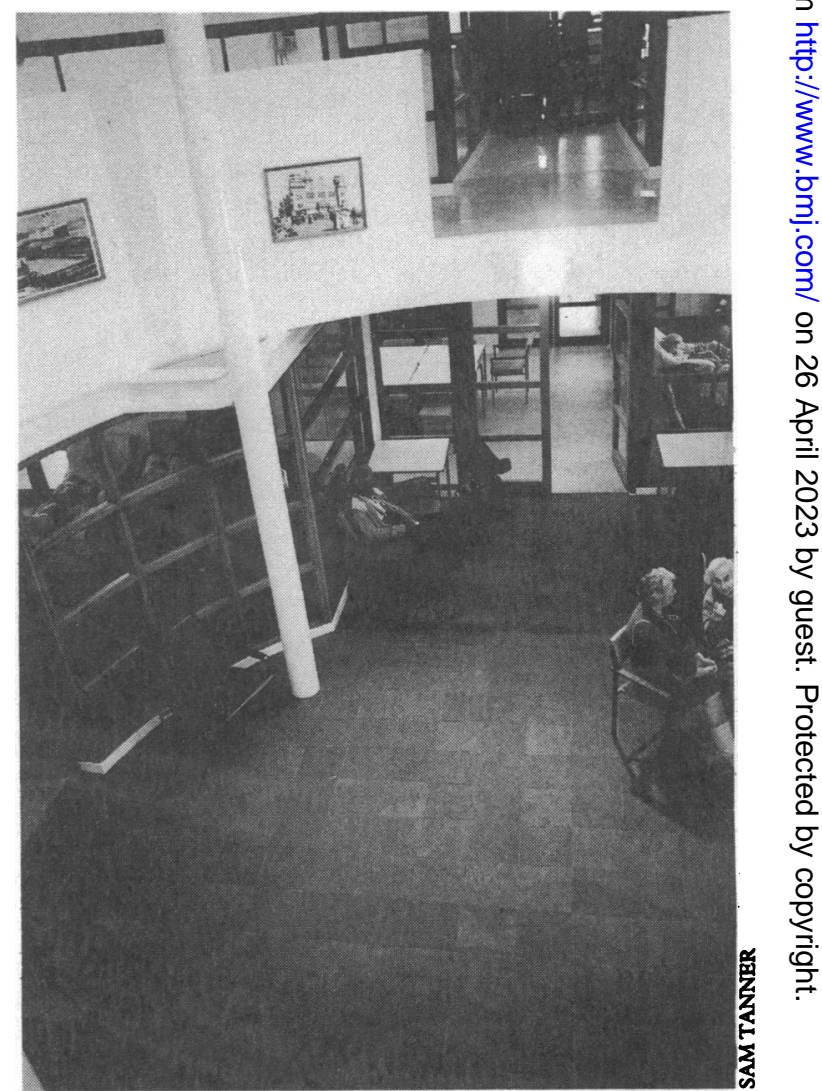

Residents meet in the communal courtyard and gallery 


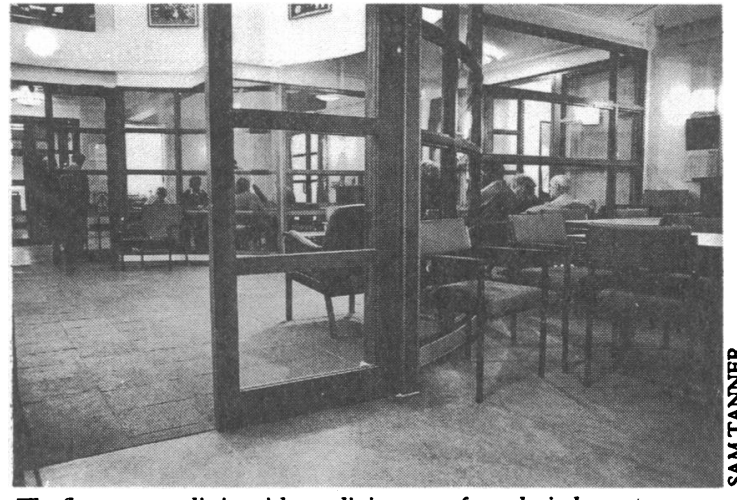

The floor texture distinguishes a dining room from the indoor street

to learn, and deal with, the fact that she is no longer in her own house and her husband is no longer alive. She cannot tolerate antidepressants, and it is difficult for her to maintain her fluid intake and weight. The staff manage her with continual reassurance and offers of food. Another woman, with isolated loss of short term memory, had flooded her house with gas, would change her mind while crossing busy roads, and kept banging on the door of the post office at night. Her recall is about 30 seconds, but she is improving as the building becomes more familiar and may be able to go to a part three home."

It is difficult to see how patients like these could be transferred back to their own homes. Dr Silverman suggested that each inner London health authority might need two or three homes like Knight's Hill, but in less densely populated areas larger numbers of smaller units might be more appropriate. "It is an expensive resource, about $£ 600$ per patient per week compared with, say, $£ 400$ for a private nursing home place, so we will have to use it selectively. The current plans for London's health service, which involve closure of general hospitals, are a threat to a unit like this which needs the support of an acute unit. We need NHS continuing care, flexible and local, linked with primary care, with day care and respite care, but we must retain the support of acute hospital psychiatric units."

The Royal College of Psychiatrists endorsed this view in its council report last year, recommending the provision of 10 acute and 25-30 long stay beds per 10000 population aged over 65 . The college said that acute beds should be on general hospital sites, but continuing care units could be in other places convenient to the community. Continuing care units

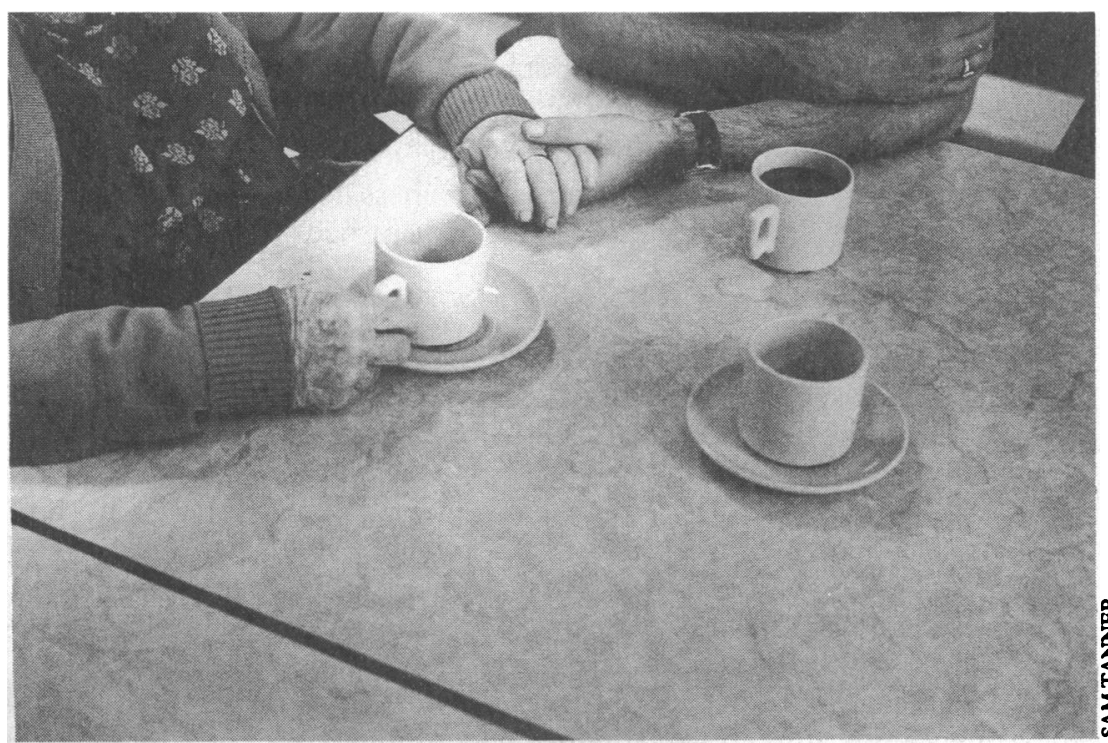

Patients and staff share facilities and eat together should have 16-24 beds, and provide day hospital facilities, training, and education. ${ }^{5}$

\section{Hospital and primary care combined}

Primary care is inextricably linked with Knight's Hill. Dr Mark Chamley, a local general practitioner, was involved in the planning meetings and now looks after the patients there. He makes regular weekly visits and, with his partners, covers the unit out of hours. "I prescribe for them, and the prescriptions are dispensed in the community, although it's a hospital unit. The nurses here are also getting used to a new situation, not having a resident doctor they can turn to, so my workload is quite heavy, but they are becoming more self reliant." Links of this kind offer general practitioners experience which may improve the standard of care for demented people in the community.

\section{A pocket of excellence or a blueprint for the future}

The mood is upbeat. Designed for its function, situated in the heart of its community, Knight's Hill is a splendid oasis of community care as the government would like us to believe it can be, within the desert of what we fear it often is. The problems are that it is expensive and needs the support of acute units which are now under threat. Using the Royal College of Psychiatrists' recommendations and the costs of care at Knight's Hill, assuming there are nine million people over 65 in the United Kingdom, residential care for the elderly costs $£ 700$ million each year. Pockets of excellence will not be sufficient to meet the needs of an increasingly elderly populace, but as Michael Manser writes, "A well designed building does not need to cost more; economies lie in the quality of thinking at the design stage." This applies to people's homes as well as institutions.

\section{Dementia care at home}

Five per cent of people over the age of 65 have some form of dementia or serious confusion of organic cause. ${ }^{7}$ Four fifths of them live at home or with relations. ${ }^{8}$ They can function better and for longer if their home design makes allowances for their deficiencies. There are many other people for whom the design of a home is not ideal, as Mary Marshall, the director of the Dementia Services Development Centre at the University of Stirling, says: "Most housing is designed for fit young men of five feet ten. Steps up to front doors that are too narrow stop prams as well as wheelchairs getting in and out. Small children cannot reach light switches, and people with bad backs cannot reach electric sockets or radiator controls that are at skirting board level." Applying these principles, the Edinvar Housing Association has now built 200 houses to a standard which aims to make all houses more accessible to and usable by everyone: "every house you'll ever need."

1 Office of Population Censuses and Surveys. Population estimates London: HMSO, 1976. (Series PPI No 1.)

2 Office of Population Censuses and Surveys. National population projections 1989 based. London: HMSO, 1991. (Series PP2 No 17.)

3 Netten $A$. The effect of design of residential homes in creating dependency among confused elderly residents: a study of elderly demented residents and their ability to find their way around homes for the elderly. Int $\mathcal{f}$ Geriat Psychiat 1989;4:143-53.

4 Marshall M. Designing for confused old people. In: Arie T, ed. Recent advances in psychogeriatrics. Vol 2. Edinburgh: Churchill Livingstone, 1992:201-16.

5 Royal College of Psychiatrists. Mental health of the nation. The contribution of psychiatry. A report of the president's working group. London: Royal College of Psychiatrists, August 1992. (Council report CR16.)

\% 6 Manser M. Design of environments. In: Jacoby R, Oppenheimer C, eds. Psychiatry in the elderly. Oxford: Oxford University Press, 1991:550-70.

7 Murphy E. After the asylums: community care for people with mental illness. London: Faber and Faber, 1991:6.

8 Burley R, Pollock R. Every house you'll ever need: designing out disorientation in the home. Stirling: Dementia Services Development Centre, University of Stirling, 1992. 